\title{
The Application and Practice of Intergenerational mentoring techniques in Guiding Entrepreneurship Education in the post-90s
}

\author{
Qiang $\mathrm{Yu}^{1, \mathrm{a}}$, Xiufeng Zou ${ }^{2, b}$, Pengbo Shang ${ }^{3, \mathrm{c}}$ \\ ${ }^{1}$ Harbin University Harbin China \\ 2 Northeast Forestry University Harbin China \\ 3 Tsinghua University Beijing China \\ ayuqiang0708@163.com, bxiufengzou@aotuke.com, 'pablo_shang@aotuke.com
}

Keywords: Intergenerational mentoring, Innovation and Entrepreneurship Education, Application and practice.

\begin{abstract}
At present, innovation and entrepreneurship education has been incorporated into the talent training program of higher education in China, which is an innovative achievement of the comprehensive reform of higher education in China. For the entrepreneurs of the post-90s generation, they are full of entrepreneurial passion and desire for success. However, because of their lack of experience, they tend to be confused and helpless in the practice of entrepreneurship. At this time, how to give effective and timely help and guidance to the entrepreneur of the post-90s college students is particularly prominent. And it's important. However, for teachers in Colleges and universities, they will also feel less confident or helpless in the face of all kinds of problems in the course of the students' entrepreneurial practice, because they have never been able to start a business and have no experience and guidance. Intergenerational tutoring technology is a set of effective techniques and methods for solving the effective communication, identification and exploring methods of teachers and students in the process of entrepreneurial practice. The article focuses on how to enhance teachers' confidence and ability in guiding students' entrepreneurial activities through intergenerational tutoring technology, how to help students recognize their own strengths and weaknesses, and to inspire their wisdom to solve their own entrepreneurial problems.
\end{abstract}

代际辅导技术在指导 “90后” 创业教育中的应用与实践

$$
\begin{gathered}
\text { 于强1, a , 邹秀峰 } 2, b \text {, 尚蓬勃 } 3, c \\
\text { 1哈尔滨学院, 哈尔滨, 中国 } \\
\text { 2东北林业大学, 哈尔滨, 中国 } \\
\text { 3清华大学, 北京, 中国 }
\end{gathered}
$$

ayuqiang0708@163.com, bxiufengzou@aotuke.com, cpablo_shang@ aotuke.com

关键词：代际辅导; 创新创业教育; 应用与实践

中文摘要. 当前, 创新创业教育已经被纳入到中国高等教育人才培养方案中, 是中国高等教 育综合改革的创新成果。对于 90 后一代大学生为主体的创业者们来说, 他们充满着创业的激 情与成功的渴望, 但是, 由于他们经验不足往往会在创业实践中陷入迷茫和无助, 这时, 如 何能够给予 90 后大学生创业者有效而及时的帮助和辅导就显得尤为突出和重要。然而, 对于 高校的教师们来说同样也会因为从来没有创业过而缺乏经验和指导的能力, 在面对 90 后们创 
业实践过程中的各类问题同样会感到信心不足或束手无策。代际辅导技术正是为解决高校师 生们在创业实践过程中如何有效沟通, 问题识别, 探寻方法的一套行之有效的技术和方法。 文章重点探讨如何通过代际辅导技术增强老师们在指导学生创业活动时的信心和能力, 如何 帮助学生认清自身的优势与不足, 启发他们的智慧解决他们自己的创业难题。

\section{1. 引言}

代际理论从社会学研究的角度被提出来可以追溯到上世纪60年代, 但是, 大多数人对于 代际理论的了解和关注应该是从 “代沟” 这个词开始的。“代沟” 产生的原因是由于不同年 龄阶段人与人之间在思想和行为等方面所表现的差异和冲突造成的, 社会发展过程由于社会 环境的变化导致代代相传的社会价值观和文化内涵在传承过程中产生了差异, 这种差异促进 了人类社会的发展和进步，也就说在人类发展进程中这种 “代差” 本是客观存在的必然结果。 然而，当 “代差” 过于巨大，就会导致文化传承的断裂甚至让不同年代的人们之间产生认同 上的极大冲突，这时 “代差” 就成了 “代沟” ，由于这道沟横贯于不同年代人们之间无法跨 越, “代沟” 所造成的冲突和矛盾就必然无法避免。被称为互联网原住民的90后一代, 他们 是中国社会改革开放以后施行计划生育政策达到顶峰效应的特殊一代人, 由于社会环境的巨 大变化, 导致90后一代独生子女的成长和教育环境发生了巨大的改变, 他们的生活享受着前 几代人不曾拥有的丰厚的物质条件, 始终处于教育服务的核心, 这让 90 后一代开始与前代人 们的传统观念和生活态度表现出越来越大的差异, 他们过度自信而疏于自我管理, 他们敢说 敢干而不计后果, 他们的这些表现是前几代人都无法理解和接受的, 这道 “代沟” 已经发展 成了 90 后与前几代人之间无法弥合的鸿沟, 以至于, 当我们想与 90 后对话的时候却无法跟他 们建立有效的沟通, 当我们想帮助他们寻找解决问题的答案时却无法能够找到他们所能接受 和认可的办法而感到束手无策。因此, 为了能够更好地与 90 后一代交流与沟通, 尤其是为了 更好地服务于 90 后大学生创业者们, 代际辅导技术便成为了实现这一目标的有力工具和手段。

\section{2. 如何认清 90 后大学生创业者的性格特征}

\section{1 “90后” 群体的两极化特征}

近年来, 随着高校创新创业教育的普及和推广，越来越多的青年大学生开始萌生创业的 想法和念头, 做为 90 后们已经成为了高校大学生创业者中的主力军。然而, 由于缺乏资源、 经验不足、团队意识差, 资金压力大等等原因导致他们并不成熟的创业梦想很难实现, 大学 生创业成功率不高, 风险极大, 往往在项目的创意阶段就因为种种困难而迷失了方向, 因此, 我们在指导 90 后大学生创业者时, 首先要做的就是要识别他们的创业能力和性格特点, 尤其 是作为创业项目的负责人或发起人, 他们的能力和性格特点往往会决定一个创业项目究竟能 够走多远。根据沙哈尔教授的汉堡模型所展现的四种幸福模式, 我们发现90后们在追求他们 的幸福时呈现出两个极端, 我们把他们称为 “小 $\mathrm{X}$ ” 和 “小 $Y$ ” 如面图1所示, 他们的行为差 异巨大，如果我们不能有效的区分他们就很难找到适合与他们建立行之有效的交流和沟通的 方式。

“小 X” 们追求的是虚无主义的幸福感，他们崇尚 “快乐至上” 却感受不到现实中的美好, 他们封闭、敏感却对追求真理不感兴趣。符合 “小 X” 特征的90后创业者, 他们在创业开始 阶段总能找到一些有别于市场规律甚至是带有恶搞性质的创业项目, 比如替人表白, 帮人占 座一类的小众化的创业项目, 他们会认为这样的项目即好玩又有市场, 但是, 在项目的执行 过程中, 他们消极的情绪会不断释放出来, 遇到困难就会退缩, 随时都会选择半途而废, 弃 创业团队中其他小伙伴和指导老师于不顾。显然, “小 “ ”们是创业教育中最难搞定的一种 类型, 如果真的发生了上面所述的情况那么这样的创业教育当然也是失败的。 
“小Y”们追求的是现实主义的幸福感，他们乐于接纳并享受现在的快乐，他们自信、 乐观并希望努力创造更好的未来。符合 “小Y” 特征的 90 后创业者, 他们能够基于市场规律 和客户需求来选择创业方向, 他们积极乐观, 且遵守自我认可的规则, 在项目的执行过程中 执行力强, 不畏惧权威, 敢于创新, 是创业教育中重点挖掘和培养的优秀创业人才。代际辅 导技术能够帮助我们的创业指导教师们慧眼识珠有效区分大学生创业者中的“小 X”和“小Y”。

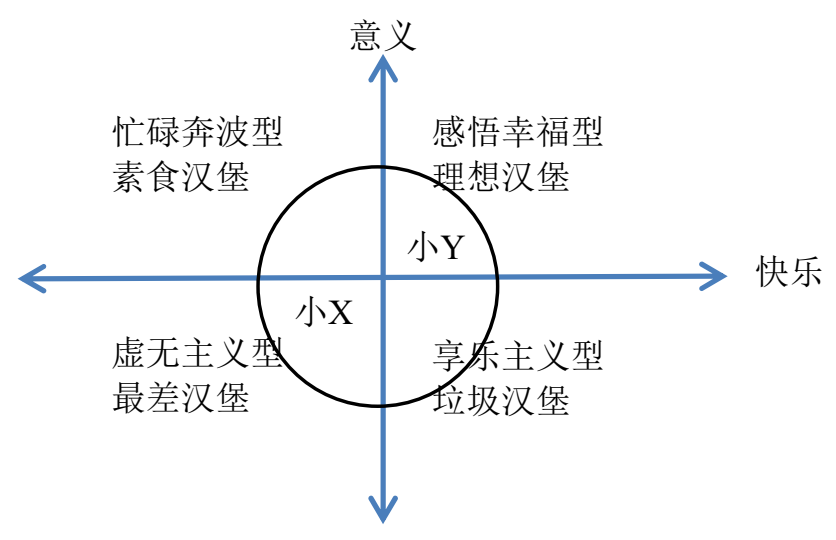

图1 90后中的 “小 X” 和 “小Y” 的幸福模式

\section{2 创业教育中如何对 “小 $X$ ” 和 “小 $Y$ ” 因材施教}

前面提到 “90后” 群体的两极化特征明显, 然而, 无论是 “小 $X$ ” 还是 “小 $Y$ ” 都是参与 创业实践活动的主体, 我们不能带着有色眼镜而排斥任何一个想要创业的学生。我们需要做 的是正确区分 “小 $X$ ” 和 “小 “ ” 根据他们不同的行为特征而因材施教。另外, 我们的教师们 还有一点误区, 以往, 我们在指导学生创业的时候, 总是习惯性地针对学生们的创业项目去 做分析和评判, 我们习惯以 “就事不就人” 的原则来与创业的学生们谈他们的创业项目, 似 乎这样更能让辅导者跟被辅导对象之间建立一道安全沟通的防火墙, 然而, 从代际辅导技术 的应用实践经验来看，我们更应该 “就人不就事” ，因为，90后们首先看重的是别人对他们 的肯定与认可, 只有基于尊重和平等的对话方式才能取得与他们有效交流和沟通的效果。因 此, 代际辅导技术在帮助创业指导教师们面对 90 后大学生创业者因材施教方面有着得天独厚 的优势。

表1 代际辅导中如何区分 “小 $X$ ” 和 “小 $Y$ ”

\begin{tabular}{|c|c|c|}
\hline & 小 $X$ & 小 $Y$ \\
\hline 心理特征 & 敏感、封闭、适应能力差 & 乐观、自信、敢于创新 \\
\hline 行为特征 & 消极、叛逆 & 积极主动 \\
\hline 需求特征 & 害怕困难 & 喜欢挑战 \\
\hline 沟通方式 & 借口多, 易逃避 & 直面困难, 信守规则 \\
\hline
\end{tabular}

根据表1所示，代际辅导技术从心理特征、行为特征、需求特征和沟通方式四个方面来帮 助我们从事创业辅导的教师们来区分 90 后中的 “小 $\mathrm{X}$ ” 和 “小 $\mathrm{Y}$ ”。我们前面说过, 无论是 “小 $X$ ” 还是 “小 $Y$ ” 都是创业实践活动的主体, 都需要创业教育给予他们必要的引导和帮助, 对 于不同类型的 90 后, 我们要在有效识别的基础上区分对待, 才能做到因材实教。

对于 “小 X” 的创业辅导要强化管理注重疏导。说到管理可能会有人不知道管理的内涵 其实包含两方面含义, 这里的 “管” 代表着 “管束” 的含义。从表1中我们可以了解到 “小X” 具有消极和叛逆的行为特征, 对于 “小 X” 们的创业方向创业导师们必需负起管束的责任, “小 X” 的创业方向允许他们另辟蹊径, 比如前面提到的 “替人表白” “帮人占座” ，但是 
一旦超出了法律或规则允许的范畴就要及时予以制止和叫停，这就是管束的含义；“理” 字 代表着 “疏导” 在含义, “小X” 具有封闭的心理特征, 遇到困难容易退缩甚至逃避, 对于 “小 X” 不能给他们施加过大的压力, 但是 “小 X” 们内敛的性格同样蕴藏着巨大的能量, 做 为他们的创业导师，要因势利导，通过合理的疏导帮助 “小 X” 们释放收敛于内的能量， “小 $\mathrm{X}$ ” 并不是不适合创业, 只是他们需要更大的勇气和更多的资源去挑战自我战胜困难,

对于 “小Y” 的创业辅导要注重激励管控风险。表1中能够看出，“小Y”们自信，敢想 敢做, 渴望接受挑战, 但是创业过程风险极大, 我们的创业导师在充分肯定和鼓励 “小Y” 的基础上最重要的是帮助他们理清现状, 识别风险, 避免不必要损失和错误, 这样才能让 “小 $\mathrm{Y}$ ”们的创业之路更加通畅, 取得更长远的成功。

\section{3. 让创业导师们成为教练型导师}

传统的创业导师习惯于经验指导，习惯于用导师的标准去评判创业者的行为，殊不知， 创业成功的标准或经验是不能够用来借鉴和复制的, 原因是任何一个创业者所面临的创业环 境和条件都是不完全一样的, 甚至是不具可比性的。代际辅导技术要求我们的创业导师要转 变成为教练型导师。创业导师不能代替创业的学生成为项目的主宰者, 导师的定位只能是教 练, 我们不能告诉创业者答案, 我们要相信每一个创业者才是他们创业领域的专家, 在充分 信任和尊重90后的基础上, 教练可以启发创业者智慧, 激发创业者潜能, 他们的智慧是解决 他们创业中各种困难的力量之源。

正如前文所述，当我们的创业导师们用一种 “就人不就事” 的原则去与90后们谈创业的 时候, 我们已经在尝试教练思维的转变了, 一个合格的教练导师一定具备四项技能: 聆听、 发问、区分和回应。聆听技术能够让教练导师彻底放空自己的态度和经验, 在尊重和认可创 业者的前提下了解创业者所要表达的事实和真相; 发问技术能够让教练导师启迪创业者的智 慧并探寻每一种可能的解决问题的方法和途径; 区分技术能够让教练导师帮助创业者理清现 状聚焦问题; 回应技术能够帮助创业者增强自信心和行动力。可见当我们掌握了教练技术不 仅极大地增强了导师的指导能力, 同时也提高 90 后大学生创业者的效率和效果, 总之, 教练 技术是代际辅导当中最有效最实用的技术, 值得当前从事创新创业教育的老师们认真学习和 借鉴。

\section{References}

[1] Qiang Yu,Lili Huang,Lin Guo,Pengbo Shang, The application and practice of the coach technique in university innovation and entrepreneurship education, Advances in Social Science,Education and research, vol.155, pp. 224-227, 2017.

[2] Xiufeng Zou, Is it suitable for college students to start a business in the era of innovation and entrepreneurship?, China University Students Career Guide, vol.10, pp. 21-23, 2018.

[3] Qingfeng Han. Gentle but powerful, China Youth Publishing House, 2014. 